\title{
Glycan FRET Probes for Screening Catalytic Antibodies against Cryptococcus neoformans Capsule
}

\author{
Conor Crawford ${ }^{1,2}$, Maggie P. Wear², Daniel F. Q. Smith², Clotilde d'Errico', Arturo Casadevall², \\ Stefan Oscarson ${ }^{1 *}$
}

${ }^{1}$ Centre for Synthesis and Chemical Biology, University College Dublin, Belfield, Dublin, Ireland, ${ }^{2}$ Department of Molecular Microbiology and Immunology, Johns Hopkins Bloomberg School of Public Health 615 North Wolfe Street, Baltimore, MD 21205, USA

\begin{abstract}
Catalytic monoclonal antibodies (mAbs) against the capsule of Cryptococcus neoformans have been identified but characterization of their Michaelis-Menten kinetics against oligosaccharides has so far not been possible. To address this, we report the design and synthesis of two glycan based Förster resonance energy transfer (FRET) probes that express a major structural unit of the cryptococcal polysaccharide. These probes allowed the kinetic analysis of four catalytic antibodies with glycosidase activity, including $2 \mathrm{H} 1$, an antibody which was not known previously to be catalytic. This is only the second report of an antibody with naturally occurring catalytic activity against glycans and the most efficient identified to date. The probe's capability as a diagnostic for catalysis was demonstrated by accurately predicting glycosidase activity on the native capsule. Furthermore, we used molecular docking studies to reveal the antibody-glycan interactions, with the first structural insights into these interactions between anti-GXM $\mathrm{mAbs}$ and their epitopes. Through modelling we see no classical catalytic residues in the antigen binding site, signifying the possibility of further glycan hydrolyzing mechanisms yet to be discovered.
\end{abstract}

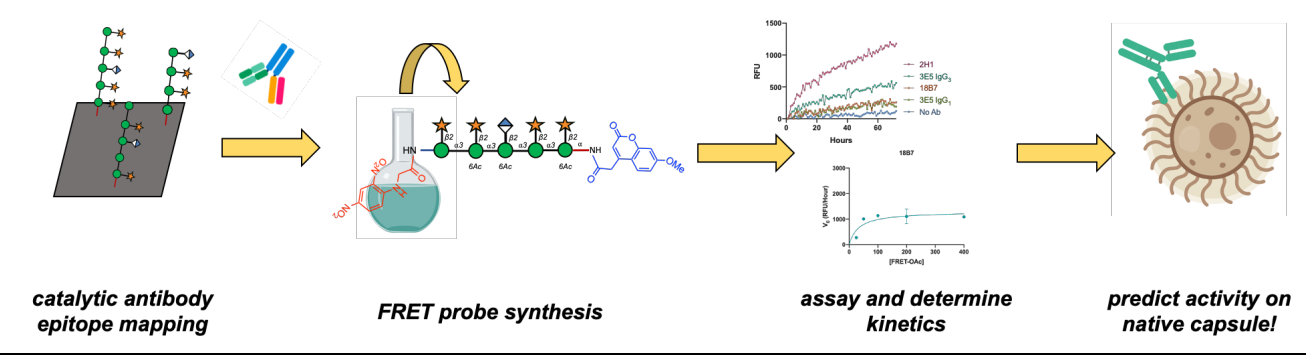

\section{INTRODUCTION}

Cryptococcus neoformans is an environmental yeast that can cause an asymptomatic pulmonary infection in early childhood but is often cleared or enters a state of latency. ${ }^{1}$ Latent cryptococcal infection can re-emerge if the host becomes immunocompromised, e.g. the host is administered immunosuppressive drugs or acquires HIV/AIDS. The infection can then spread systemically causing cryptococcal meningitis. It is estimated there are 1 million infections annually, with over 600,000 deaths. ${ }^{2}$ In an effort to develop therapeutics to combat this infection, both native and semisynthetic conjugate vaccines have been investigated using the polysaccharide capsule of C. neoformans. ${ }^{3-5}$ The capsule is composed of several constituents; galactoxylomannan (GalXM), mannoproteins, $\quad \beta$-glucans and glucuronoxylomannan (GXM). The latter dominates, accounting for $95 \%$ of capsule mass, composing of a linear $\alpha-$ $(1 \rightarrow 3)$-mannose backbone, with $\beta-(1 \rightarrow 2)$ and $\beta-(1 \rightarrow 4)$ xylose branches, $\beta-(1 \rightarrow 2)$ glucuronic acid branches and an 6-Oacetylation pattern along the mannan backbone. ${ }^{6-8}$
Using hybridoma technology monoclonal antibodies (mAbs) have been developed against the GXM, that serve as tools for research, diagnostics, and therapeutics. ${ }^{9}$ One antibody against GXM, 18B7, was used in a phase I clinical trial as a candidate for passive antibody therapy for cryptococcal infections. ${ }^{10}$ In later years, this anti-GXM antibody and others were serendipitously discovered to have catalytic activity against their oligosaccharide epitopes, and also curiously against peptide mimetics of the GXM. ${ }^{11}$ Catalytic antibodies were first hypothesized by biochemist William Jencks in the 1980s, using the framework of Linus Pauling that if an antibody was raised against a transition state analogue it could possibly cleave its substrate. Since then they have been an area of intensive research. ${ }^{12-14}$ Antibodies with catalytic activity have been both rationally designed and the subject of accidental discovery, with Richard Lerner and coworkers proposing the intriguing innate capabilities such as catalyzing the breakdown of oxygen into hydrogen peroxide. ${ }^{11,15-17}$ While Hifumi et al. screened libraries of antibody light chains to discover one with catalytic activity against amyloid-beta using a FRET peptide. ${ }^{18}$ Despite research, the role(s) of catalytic antibodies in immunity is currently 
unresolved, with their discovery in both patients with healthy outcomes and autoimmune conditions. Catalytic antibodies generally have much lower efficiency in catalyzing their reactions in terms of turnover number $\left(k_{c a t}\right)$, when compared to their enzyme counterparts, however, mAbs also tend to have much greater affinity for their substrates i.e. Michaelis-Menten constant $\left(K_{\mathrm{m}}\right)$. This sometimes leads to a peculiar conundrum, when expressed through the catalytic efficiency equation $k_{\text {cat }} / K_{\mathrm{m}}$, that catalytic mAbs have greater 'catalytic efficiency'. The relevancy of this currently enigmatic quality is still unclear. One particular area where antibody catalysis may be relevant is in infectious diseases research, as catalytic antibodies could be effective, even if relatively slow, against microbial antigens as these infections often take time to develop. In addition, catalytic mAbs may work through revealing more immunogenic epitopes to the immune system, aiding immune detection and increasing the potency of antibody-dependent cellular cytotoxicity.

Recently, Bowen et al. used a P1 peptide (GXM mimetic) equipped with the FRET pair 7-methoxycoumarin-4-acetic acid (MCA) and 2,4-dinitrophenyl (DNP) to quantify 18B7's peptidase activity. ${ }^{11}$ With obvious limitations in extrapolating peptide hydrolysis to glycan hydrolysis, in this work we use the principle of Förster resonance energy transfer (FRET) to design probes to uncover the catalytic activity of anti-GXM mAbs. We report the design and synthesis of two decasaccharide FRET probes that bare the same saccharide sequence but differ in acetylation pattern. Synthesis of glycan-based FRET probes in comparison to the peptide counterparts is significantly underdeveloped, with a handful of literature reports. ${ }^{19-22}$ There are also reports of glycan-based FRET probes, using native polysaccharides e.g. heparin, which are then derivatized with a FRET pair. ${ }^{23,24}$ This to the best of our knowledge is the first example of glycan-based FRET probes being used to resolve the Michaelis-Menten kinetics of catalytic antibodies. In this report, we use these FRET probes to detail the catalytic activity of four catalytic antibodies against GXM, including one antibody not previously known to be catalytic, noting this as the second antibody ever identified to have innate catalytic activity against its glycan epitope. ${ }^{11}$ We then performed antibodyantigen docking experiments, hoping to discern the catalytic residues responsible for the hydrolytic activity of $\mathrm{mAb} 2 \mathrm{H} 1$.

\section{RESULTS AND DISCUSSION}

There are few literature examples of glycan FRET probes and none, to our knowledge, have been used to investigate the activity of catalytic antibodies. ${ }^{21,25}$ The synthesis of GXMbased FRET probes is complicated by the presence of a $6-O$ acetylation pattern, shown to be important in antibody recognition and epitope presentation, which limits protecting group strategies. To discern the importance of the 6-Oacetylation in recognition, and therefore catalysis, we prepared two FRET probes one acetylated and one non-acetylated. The target FRET probe was rationally designed from glycan array screening data showing an acetylated decasaccharide (Figure 1) to be recognized by a variety of monoclonal antibodies, including mAbs $18 \mathrm{~B} 7$ and $3 \mathrm{E} 5$ which have been suggested to be catalytic. ${ }^{11,26}$ Further we confirmed the importance of the 6$O$-acetylation through a microarray study (Figure 1). In which we found the binding to the non-acetylated decasaccharide was significantly diminished for $18 \mathrm{~B} 7$ and for all other mAbs screened binding was lost entirely (Figure 1).
A

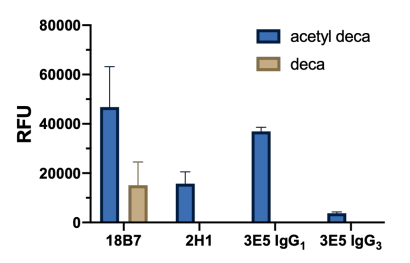

B

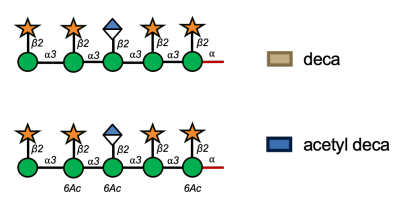

Figure 1. Effect of acetylation on antibody recognition. A Glycan microarray data showing antibody binding is affected by acetylation of GXM. Bars represent the mean \pm SD. B The structures of the decasaccharides are depicted according to symbol nomenclature for glycans (SNFG). ${ }^{27}$

\section{Synthesis of FRET probes}

We planned to use the aminoalkyl linker present at the reducing end as a handle for the attachment of one half of the FRET pair. Then functionalize the non-reducing end with an amino linker, ultimately designing a probe with two orthogonal nitrogen atoms at apposing ends of the oligosaccharide, to allow selective attachment of the fluorophore and quencher to access the desired glycan FRET probes.

Synthesis and assembly of the required building blocks for GXM assembly used published protocols, with minor deviations noted in experimental procedures. ${ }^{28-33}$ Disaccharide acceptor 1 was coupled with thioglycoside donor $\mathbf{2}$ using DMTST in ether, ${ }^{34}$ following purification the 2-naphthylmethyl (NAP) ether was removed using 2,3-dichloro-5,6-dicyano-1,4benzoquinone (DDQ) with a buffered aqueous component to suppress unwanted benzyl group cleavage (Scheme 1A). Tetrasaccharide acceptor $\mathbf{4}$ was then coupled with a glucuronic acid containing disaccharide to create hexasaccharide 6 in $63 \%$ yield following purification. Orthogonal NAP cleavage was completed using the optimized conditions, to access hexasaccharide acceptor 7 .

Initially, attempts using various $N$-tert-butyloxycarbonyl $(N$ Boc)-protected donors failed to yield the desired $N$ orthogonally functionalized oligosaccharides. Glycosylation with these donors produced complex reaction mixtures, as visualized through thin-layer chromatography (TLC), with no major product visible. We reasoned that the complex reaction mixtures were due to the acidic nature of the DMTST promoted glycosylation, causing the cleavage of the $N$-Boc protecting group. Despite this hypothesis, attempts to buffer the reaction with 2,4,6-tri-tert-butylpyrimidine failed to rectify the glycosylation conditions, therefore it was decided to use a $N$ phthalimido protecting group for the glycosylation conditions which could then be substituted over two steps to the desired $N$-Boc protecting group before the palladium catalyzed hydrogenolysis.

The tetrasaccharide $\mathbf{8}$ was assembled using inverseglycosylation conditions as described by Guazzelli et al., ${ }^{35}$ and the aminopropyl handle successfully attached under alkylating conditions, in the presence of the 6-O-acetylation pattern $(70 \%$ of isolated yield), with only minor de-acetylation occurring $(8 \%$ of isolated yield) (Scheme 1B). Donor 9 was then used successfully to create the $N$-orthogonally functionalized decasaccharide 10 in $85 \%$ yield. The $N$-phthalimido protecting group was then selectively cleaved in the presence of primary 6-O-acetylation pattern using ethylenediamine, followed by formation of the $N$-Boc protected compound 11 in $57 \%$ yield. 



${ }^{a} \mathbf{A}$ Reagents and Conditions: a) DMTST, Et $2 \mathrm{O}, 4 \AA \mathrm{MS}, 0^{\circ} \mathrm{C} \rightarrow \mathrm{rt}, 80 \%$ : b) DDQ, $\mathrm{CH}_{2} \mathrm{Cl}_{2}: \mathrm{PBS}(100 \mathrm{mM}, \mathrm{pH} 7.5)(85: 15 \mathrm{v} / \mathrm{v}), 0^{\circ} \mathrm{C}$, 76\%: c) DMTST, Et $2 \mathrm{O}, 4 \AA \mathrm{MS}, 0^{\circ} \mathrm{C} \rightarrow \mathrm{rt}, 65 \%$ : d) DDQ, $\mathrm{CH}_{2} \mathrm{Cl}_{2}: \mathrm{PBS}(100 \mathrm{mM}, \mathrm{pH} 7.5)(85: 15 \mathrm{v} / \mathrm{v}), 0^{\circ} \mathrm{C}, 70 \%$. B Reagents and Conditions: a) $\mathrm{NaH} 60 \%$ dispersion in mineral oil, DMF, $4 \AA \mathrm{MS}$, PhthNCH $\mathrm{CH}_{2} \mathrm{CH}_{2} \mathrm{Br}, 0^{\circ} \mathrm{C} \rightarrow \mathrm{rt}, 70 \%$ : b) DMTST, Et 2 , $4 \AA \mathrm{MS}$, $0^{\circ} \mathrm{C} \rightarrow \mathrm{rt}, 85 \%$ : c) ethylene diamine, $\left.n-\mathrm{BuOH}, 90^{\circ} \mathrm{C}: \mathrm{d}\right) \mathrm{Boc}_{2} \mathrm{O}, \mathrm{THF}: \mathrm{H}_{2} \mathrm{O}(70: 30 \mathrm{v} / \mathrm{v}), 57 \% 2$ steps: f) $\mathrm{Pd} / \mathrm{C}$ (pre-treated catalyst), $\mathrm{H}_{2}$, THF: ${ }^{t} \mathrm{BuOH}: \operatorname{PBS}(100 \mathrm{mM}, \mathrm{pH} 5)(60: 10: 30 \mathrm{v} / \mathrm{v} / \mathrm{v}), 66 \%$.

When synthetic GXM structures are subject to palladium catalyzed hydrogenolysis conditions, a portion of the benzyl protecting groups are saturated to the corresponding cyclohexylmethyl ethers. ${ }^{36}$ To suppress this, we used our described pre-treated palladium catalyst to suppress this sideproduct formation. ${ }^{36}$ Decasaccharide 12 was then subject to global deprotection, and pleasingly the desired decasaccharide 13 was isolated after P-2 size exclusion chromatography with no saturation side-products observed (Scheme 1B). Due to the limited quantity of material available it was decided to telescope the final steps as to minimalize the loss of material. Firstly, the fluorophore was conjugated to the amino linker using an $N$ hydroxysuccinimide (NHS) active ester of MCA, to produce compound 14 (Scheme 2). Subsequently, the $N$-Boc was removed using an aqueous mixture of $3 \mathrm{M} \mathrm{HCl}$ methanol to produce 15. The final conjugation was carried out using the NHS activated $N$-(2,4-Dinitrophenyl) glycine (DNP) to give $5.4 \mathrm{mg}$ of the desired FRET probe $\mathbf{1 6}$ in $56 \%$ yield.
Despite initial evidence that non-acetylated structures are poorly recognized (Figure 1), we decided to further investigate the importance of the 6-O-acetylation pattern in the antibody recognition and catalysis. This was complete by deacetylation of a portion of the decasaccharide FRET-OAc probe using basic aqueous conditions to yield $2 \mathrm{mg}$ of FRET probe 17 . The two probes were then termed 'FRET-OAc' (16), for the decasaccharide with acetyl groups, and 'FRET' (17) for the deacetylated decasaccharide.

\section{A FRET assay to Detect of Catalytic Antibodies}

Four murine monoclonal antibodies were investigated: 18B7 $\left(\operatorname{IgG}_{1}\right), 2 \mathrm{H} 1\left(\operatorname{IgG}_{1}\right)$, and two isotypes of $3 \mathrm{E} 5$ an $\operatorname{IgG}_{1}$ and $\mathrm{IgG}_{3}$, which have identical variable regions but differ in constant region. mAbs $2 \mathrm{H} 1,18 \mathrm{~B} 7$ and $3 \mathrm{E} 5\left(\mathrm{IgG}_{3}\right)$ were generated from $B$ cells harvested from the spleen on mice immunized with the GXM-tetanus toxoid conjugate vaccine, ${ }^{37}$ while mAb 3E5 $\left(\mathrm{IgG}_{1}\right)$ was generated by in vitro isotype switching. ${ }^{38}$ 




${ }^{a}$ The synthesis of the two FRET probes was telescoped over several steps in order to minimize material loss. FRET-OAc 16 bears a 6-Oacetylation pattern, while FRET 17 in contrast bears the same glycan sequence but no acetylation pattern $(*=$ no 6-OAc).

Table 1. Michaelis-Menten Kinetics of $2 \mathrm{H} 1$ and 18B7

\begin{tabular}{|c|c|c|c|c|c|}
\hline Entry & Antibody & FRET Probe & $\mathrm{Km}[\mathrm{mM}]$ & kcat $\left[\mathrm{s}^{-1}\right]$ & $\mathrm{kcat} / \mathrm{Km}\left[\mathrm{mM}^{-1} / \mathrm{s}^{-1}\right]$ \\
\hline 1 & $18 \mathrm{~B} 7$ & 17 & ND & ND & ND \\
\hline 2 & $2 \mathrm{H} 1$ & 17 & $1.8 \times 10^{-4}$ & $6.16 \times 10^{-3}$ & 37 \\
\hline 3 & 18B7 & 16 (OAc) & $6.6 \times 10^{-4}$ & $1.35 \times 10^{-2}$ & 21 \\
\hline 4 & $2 \mathrm{H} 1$ & $16(\mathrm{OAc})$ & $2.12 \times 10^{-4}$ & $1.3 \times 10^{-2}$ & 61 \\
\hline
\end{tabular}
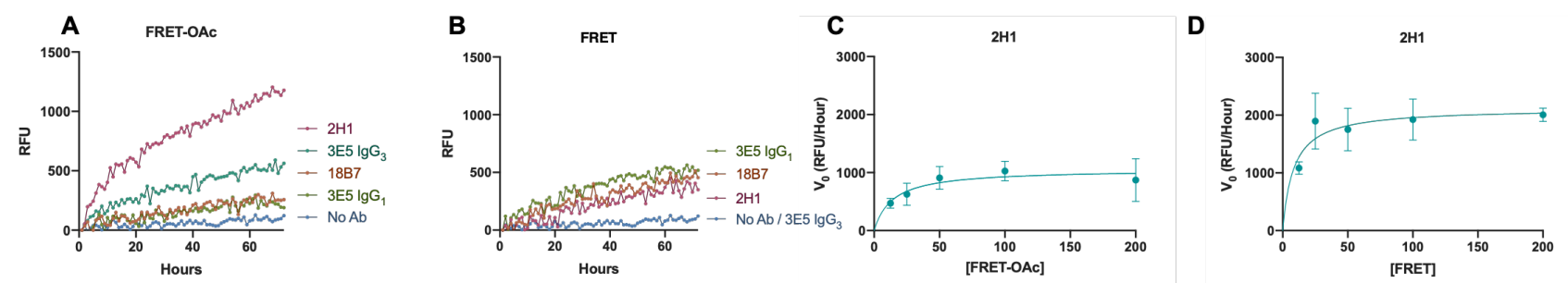

Figure 2. Utility of Glycan Based FRET Probes. A, B Use of FRET probes as an assay to detect catalytic antibodies C, D Characterization of $\mathrm{mAb} 2 \mathrm{H} 1$ 's Michaelis-Menten kinetics towards FRET probes $\mathbf{1 7}$ and 16. The initial velocity $\left(\mathrm{V}_{0}\right)$ of each reaction was determined and plotted as a function of substrate concentration, the data was fit to the Michaelis-Menten equation for a singlestep bimolecular reaction using nonlinear regression. $K_{\mathrm{m}}$ and $k_{\text {cat }}$ were calculated using Prism 8 . Each point represents $\mathrm{n}=3$ and bars represent the mean $\pm \mathrm{SD}$.

Each of these mAbs bind to the GXM capsular polysaccharide of $C$. neoformans. mAbs $18 \mathrm{~B} 7$ and the two $3 \mathrm{E} 5$ isotypes were previously shown to be catalytic towards cleaving a peptide mimetic of the GXM, termed P1 (SPNQHTPPWMLK). ${ }^{11,16}$ Incubating $\mathrm{mAb} 2 \mathrm{H} 1$ with the P1 peptide at $37^{\circ} \mathrm{C}$ also led to cleavage of the $\mathrm{P} 1$ peptide, as was suggested by the disappearance of the starting material ion $1435.7 \mathrm{~m} / \mathrm{z}$, and the appearance of fragment ions (SI, Figure 2). MS spectra of the P1 peptide post-incubation contained an ion at $690.9 \mathrm{~m} / z$ which corresponded to cleavage between threonine and proline (SPNQHT/PPWMLK). However, it was not possible to identify the other half of this fragment at $769.4 \mathrm{~m} / \mathrm{z}$ (PPWMLK). This ion suggests mAb 2H1 caused cleavage between the same residues as $\mathrm{mAb} 18 \mathrm{~B} 7$ (threonine and proline) but differed to the cleavage pattern of the 3E5 antibodies (SPNQHTPPWM/LK). ${ }^{11}$ Next, we used a P1q FRET $(200 \mu \mathrm{M})$ peptide recently described by Bowen et al. to confirm that $2 \mathrm{H} 1(375 \mu \mathrm{g} / \mathrm{mL})$ had hydrolytic activity towards the peptide probe but at much lower levels of comparatively to 18B7 (SI, Figure 1).
mAbs 18B7, 3E5 (IgG 1$), 3 E 5\left(\operatorname{IgG}_{3}\right)(800 \mu \mathrm{g} / \mathrm{mL})$ and $2 \mathrm{H} 1$ $(580 \mu \mathrm{g} / \mathrm{mL})$ were incubated with $400 \mu \mathrm{M}$ of the oligosaccharide FRET probes 16 (FRET-OAc) and 17 (FRET) in a fluorescence spectrometer $\left(\lambda_{\text {ex }} 320 \mathrm{~nm} \lambda_{\text {em }} 405 \mathrm{~nm}\right)$ at 37 ${ }^{\circ} \mathrm{C}$ for 70 hours (Figure 2A, 1B). mAb 18B7 showed moderate catalytic activity towards both FRET probes, however, change in RFUs over time was slightly higher for the FRET probe 17, possibly indicating a difference in antibody recognition based on acetylation and slower cleavage of the acetylated FRET probe 16. mAb 3E5 $\left(\operatorname{IgG}_{1}\right)$ displayed comparable results to mAb 18B7 when incubated with FRET probe 17 and showed little to no activity towards the FRET-OAc probe $\mathbf{1 6 .}$ Interestingly, the $\mathrm{IgG}_{3}$ variant of $3 \mathrm{E} 5$ differed in specificity towards the FRET probes $\mathbf{1 6}$ and $\mathbf{1 7}$ when compared to 3E5$\mathrm{IgG}_{1}$, displaying no catalytic activity towards the deacetylated FRET probe 17, in contrast to the $\mathrm{IgG}_{1}$ variant which displayed the highest change in fluorescence of the four mAbs tested. However, mAb 3E5 ( $\left.\operatorname{IgG}_{3}\right)$ showed the second highest efficiency in cleaving the FRET-OAc probe $\mathbf{1 6}$. 
A

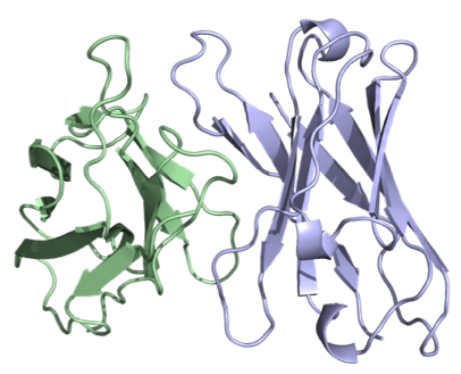

C

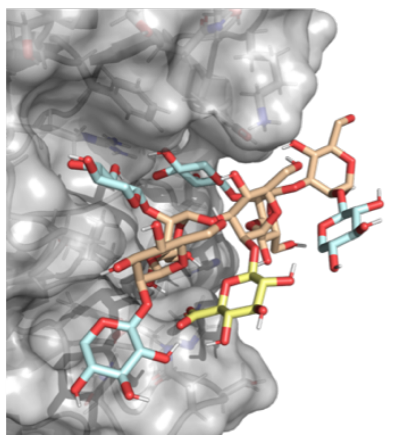

B
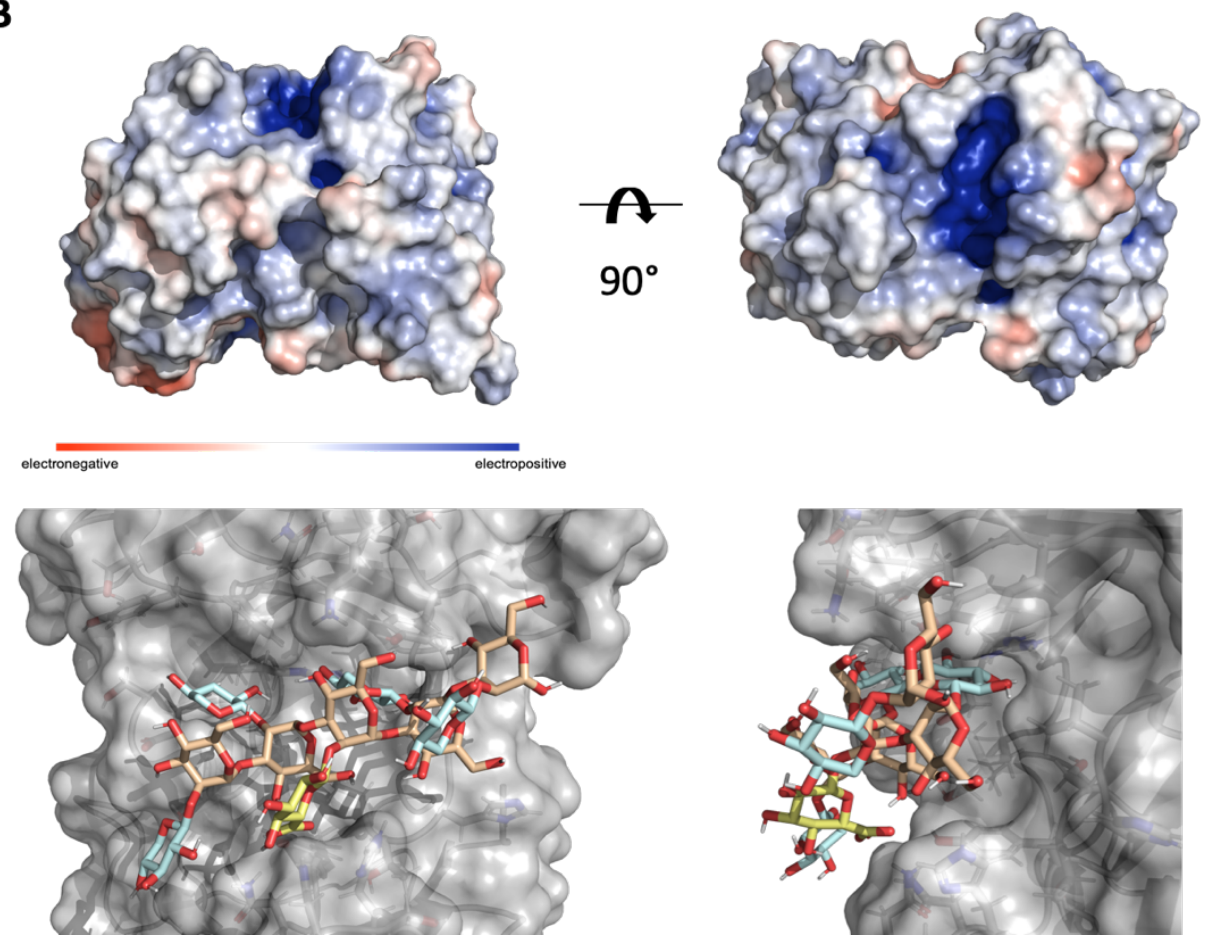

Figure 3. Modelling interactions between $2 \mathrm{H1}$ and its decasaccharide substrate. A crystal structure of anti-GXM mAb $2 \mathrm{H} 1$. VH shown in light blue and VL light chain shown in pale green. B Calculated electrostatic surface potential of 2H1. Electrostatic surface potentials are colored red for negative charges, blue for positive charges, and white color represents neutral residues. Electrostatic surface potential was calculated using adaptive Poisson-Boltzmann solve (APBS) in PyMOL. mAb 2H1 shows a positively charged cleft $(+10 \mathrm{kT}$ to $-10 \mathrm{kT})$. C Decasaccharide ligand is color coded according to monosaccharide composition. Mannose (tan), glucuronic acid (bright yellow), and xylose (pale blue). Glycam Carbohydrate Builder was used to construct ligand and perform antibody docking. Highest-scoring ligand conformers were exported for figure creation in PyMOL (Version 2.0.7).

When considering the catalytic activities of the two isotypes of $\mathrm{mAb} 3 \mathrm{E} 5$, these results suggest the constant region effects catalysis. Incubation of mAb $2 \mathrm{H} 1$ with the FRET probes resulted in the greatest cleavage of the FRET-OAc probe 16, as suggested by the increased fluorescence emission, while showing similar levels of activity towards the FRET probe $\mathbf{1 7}$ to $\mathrm{mAbs} 18 \mathrm{~B} 7$ and $3 \mathrm{E} 5\left(\mathrm{IgG}_{1}\right)$ (Figure $2 \mathrm{~A}, 2 \mathrm{~B}$ ) these experiments confirmed for the first time all the antibodies displayed some level of glycosidase activity towards at least one the oligosaccharide FRET probes. Notably some mAbs displayed no activity towards one FRET probe but hydrolytic activity towards the other (e.g. $3 \mathrm{E} 5 \mathrm{IgG}_{3}$ ), suggesting that the acetylation pattern was important in antigen-antibody binding. The importance of acetylation was also suggested by the microarray binding study (Figure 1), but in contrast mAbs $2 \mathrm{H} 1$ and $3 \mathrm{E} 5-\mathrm{IgG}_{1}$ which did not bind on the microarray, did display hydrolytic activity to the deacetylated FRET probe 17 . This contradiction might be rationalized by the addition of the hydrophobic FRET pair which could increase the binding affinity of the oligosaccharide to the protein.

\section{Investigation of Michaelis-Menten Kinetics of $2 \mathrm{H1}$ and 18B7}

Next we sought to determine the Michaelis-Menten (MM) kinetics of mAbs 2H1 and 18B7 against both FRET probes. To do this, we incubated both antibodies with varying concentrations of the FRET probes $\mathbf{1 6}$ or $\mathbf{1 7}$ and plotted the change in velocity $\left(\mathrm{V}_{0}\right)$ as a function of substrate concentration
(Figures 2A, 2B, Table 1). In the case of mAb $18 \mathrm{~B} 7$ we were unable to get reproducible data to determine its MM kinetics towards the deacetylated FRET probe 17 (Table 1, Entry 1), but in the case of FRET-OAc we managed to determine the kinetics (SI Figure 5, Table 1, Entry 3). Also mAb 18B7 has previously had its MM kinetics described by Bowen et al. for its kinetic activity against P1q. ${ }^{11}$ The $K_{\mathrm{m}}$ of $18 \mathrm{~B} 7$ towards the P1q FRET peptide ranged from 46 to $55 \mu \mathrm{M}$. This is approximately 70 times lower affinity for the peptide substrate vs. the oligosaccharide substrate, which is not unsurprising given that this antibody was raised against an oligosaccharide epitope. The $k_{\text {cat }}$ values of mAb 18B7's cleavage of FRET-OAc probe was at least 4-fold of that measured for mAb 18B7s cleavage of P1q peptide.

To compare the activity of $18 \mathrm{~B} 7$ to that of $2 \mathrm{H} 1$ we calculated the MM kinetics of $\mathrm{mAb} 2 \mathrm{H} 1$ for both FRET probes $\mathbf{1 6}$ and $\mathbf{1 7}$ (Table 1, Entry 2 and 4). For 2H1 we also observed difference in activity between FRET probes $\mathbf{1 6}$ and $\mathbf{1 7}, \mathrm{mAb} 2 \mathrm{H1}$ 's $K_{\mathrm{m}}$ towards the FRET probe had a $K_{\mathrm{m}}$ of $1.8 \times 10^{-4} \mathrm{mM}$, while FRET-OAc had a $K_{\mathrm{m}}$ of $2.12 \times 10^{-4} \mathrm{mM}$ (Figure 3C, 3D). Suggesting $2 \mathrm{H} 1$ had a slightly higher affinity for the deacetylated FRET probe. The $k_{\text {cat }}$ of $2 \mathrm{H} 1$ towards deacetylated FRET probe 17 was $6.16 \times 10^{-3} \mathrm{~s}^{-1}$, while FRET-OAc 16 was 1.3 $\mathrm{x} 10^{-2} \mathrm{~s}^{-1}$, suggesting $2 \mathrm{H} 1$ was twice as efficient at hydrolyzing the acetylated FRET probe. This is thought provoking as the $K_{\mathrm{m}}$ data suggested the de-acetylated probe has marginally higher affinity, but this did not lead to greater efficiency in FRET probe cleavage. 
While it was not possible to compare the activity of $18 \mathrm{~B} 7$ and $2 \mathrm{H} 1$ towards the deacetyl FRET probe 17, it was possible with the acetylated FRET probe 16 . While the affinity $\left(K_{\mathrm{m}}\right)$ of $2 \mathrm{H} 1$ towards the decasaccharide was 3-fold that of 18B7 (Table 1), the $k_{\text {cat }}$ of both antibodies towards the FRET-OAc probe were similar. Overall, when expressed through the catalytic efficiency equation $\left(k_{\text {cat }} / K_{\mathrm{m}}\right)$ (Table 1$), \mathrm{mAb} 2 \mathrm{H} 1$ is three times more efficient at hydrolysis than $18 \mathrm{~B} 7$, leading to us to propose $2 \mathrm{H} 1$ is much more efficient at catalyzing the hydrolysis of GXM oligosaccharides. Comparing the catalytic activity of mAbs $2 \mathrm{H} 1$ or $18 \mathrm{~B} 7$ to glycosidase enzymes reveals that while they have lower $k_{\text {cat }}$ values than that of classical enzymes, ${ }^{39}$ they also have far greater affinity for their substrates then conventional glycosidases. ${ }^{11,16,39}$ For example, comparing an exoglycanase isolated from Cellulomonas fimi with a $K_{\mathrm{m}}$ ranging from $1.7-66.4 \mathrm{mM}^{39}$ to catalytic antibody $2 \mathrm{H} 1$ with a $K_{\mathrm{m}} 1.8-2.12 \times 10^{-4} \mathrm{mM}$, clearly $2 \mathrm{H} 1$ has a higher affinity. Therefore, when we compare the catalytic efficiencies $2 \mathrm{H} 137$ $61 \mathrm{mM}^{-1} / \mathrm{s}^{-1}$ vs. C. fimi exoglycanase $2.1 \times 10^{-4}-9.5 \mathrm{mM}^{-1} / \mathrm{s}^{-1}$ it is clear that while catalytic antibodies have a lower activity, their higher affinity results in an overall higher catalytic efficiency than their enzymatic counterparts.

To investigate where the cleavage of the FRET probe was taking place by $2 \mathrm{H} 1$, we incubated it with a synthetic oligosaccharide for 2 days at $37{ }^{\circ} \mathrm{C}$. Cleavage of the oligosaccharide was suggested by disappearance ion at 1701.5 $\mathrm{m} / \mathrm{z}$ (SI, Figure 3) and the appearance of fragments. However, it was not possible to confirm the specificity of $2 \mathrm{H} 1$ by $\mathrm{MS}$ analysis by assigning the ions. The absence of specific fragments could suggest that $2 \mathrm{H} 1$ can hydrolyse the synthetic glycan repeatedly into small fragments and therefore complicate exact assignment.

\section{Antibody-glycan docking studies}

The catalytic activity of mAb 18B7 was recently studied in detail and catalytic residues were proposed, ${ }^{11}$ however a crystal structure does not yet exist. In contrast a crystal structure of the fragment antigen-binding (Fab) domain of $2 \mathrm{H} 1$ bound to a peptide mimetic of GXM was solved by Young and co-workers (Figure 3A). ${ }^{40}$ Using the PDB file and Robert Wood's open access modelling server GLYCAM, ${ }^{41-43}$ we performed antibody docking studies to inform us on the decasaccharide-antibody interactions (Figure 3C). The highest scoring binding affinities were predicted to be $-10 \mathrm{kcal} / \mathrm{mol}$ for both acetylated and deacetylated structures, although the validity of this prediction is questionable based on experimentally observed differences. When we applied an adaptive Poisson-Boltzmann solver (APBS) to the 2H1 Fab, it revealed an electropositive cleft (Figure 3B). Considering that GXM is an anionic polysaccharide, this electropositive cleft suggests a role for ionic interactions in affinity between the antibody and antigen. This is further supported by the highest scoring docked structures which show the carboxylic acid moiety of glucuronic acid residue in close contact with asparagine residues (ca. $3 \AA$ ) suggesting a stabilization by cation-anion interactions (Figures 3C, 4A). The importance of xylose substitution was also apparent by the modelling results with the highest scoring docking structures having xylose branches in pockets underneath tyrosine and phenylalanine residues, possibly being stabilized by $\mathrm{CH} / \pi$ stacking (Figure $4 \mathrm{~A}) .{ }^{44}$ We also sought through modelling if we could discern the residues responsible for catalysis, and while no definitive assignment was possible, it was clear that no classical catalytic residues were present in the antigen binding site e.g. two carboxyl groups $10 \AA$ apart, ${ }^{45}$ or the classical Ser-His-Asp catalytic triad, that was proposed by Bowen et. al. to be responsible for the cleavage of the P1 peptide by $18 \mathrm{~B} 7 .{ }^{11}$

A

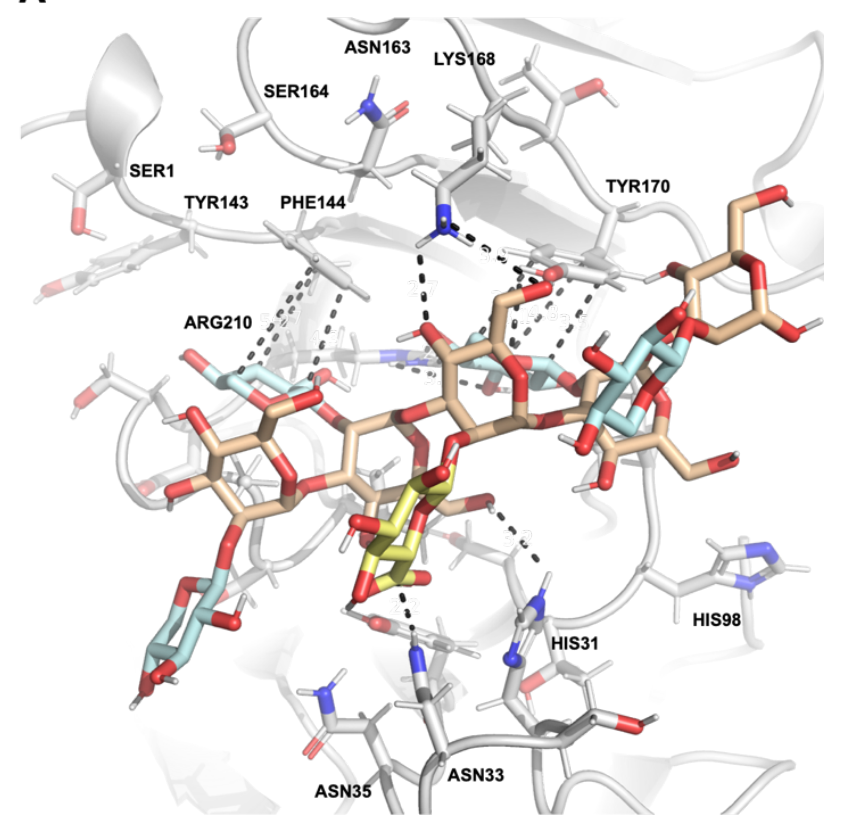

B



C

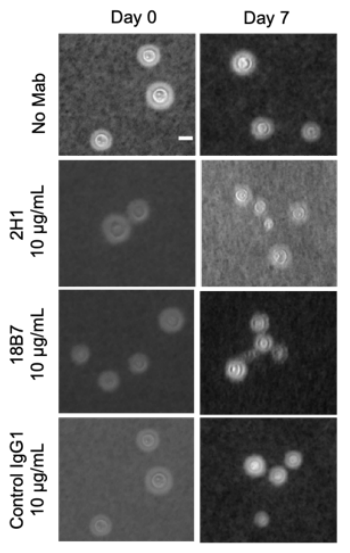

Figure 4. Incubation of mAb $2 \mathrm{H} 1$ causes decrease in mean capsule diameter of $\boldsymbol{C}$. neoformans cells capsule. A in silico modelling reveals $2 \mathrm{H} 1$ does not contain classical catalytic residues in antigen binding site. Transparent surface representation of $2 \mathrm{H} 1$ structure with the ligand decasaccharide. The ligand is color coded according to monosaccharide composition. Mannose (tan), glucuronic acid (bright yellow), and xylose (pale blue). Amino acid side chains in binding site are labelled according to appearance in primary sequence and heteroatoms are detonated in color, nitrogen (blue) and oxygen (red). Dashed lines indicate proposed H-bonds. All interaction distances are less than $4.1 \AA$. B Heat-killed $C$. neoformans cells were incubated with $18 \mathrm{~B} 7,2 \mathrm{H} 1$, a control $\mathrm{IgG}_{1}$ antibody and no antibody for 7 days. Capsule measurements revealed a statistically significant (Ordinary one-way ANOVA) decrease in mean capsule diameter when incubated with 18B7 or $2 \mathrm{H} 1$ but not in control experiments. Each group contained at least 100 capsule measurements $(* * * *, p<0.0001$.) $\mathbf{C}$ Images of heatkilled fungal cells under each antibody condition at both day 0 and day 7. India ink stain allows visualization of capsule diameter. Scale $10 \mu \mathrm{m}$. 


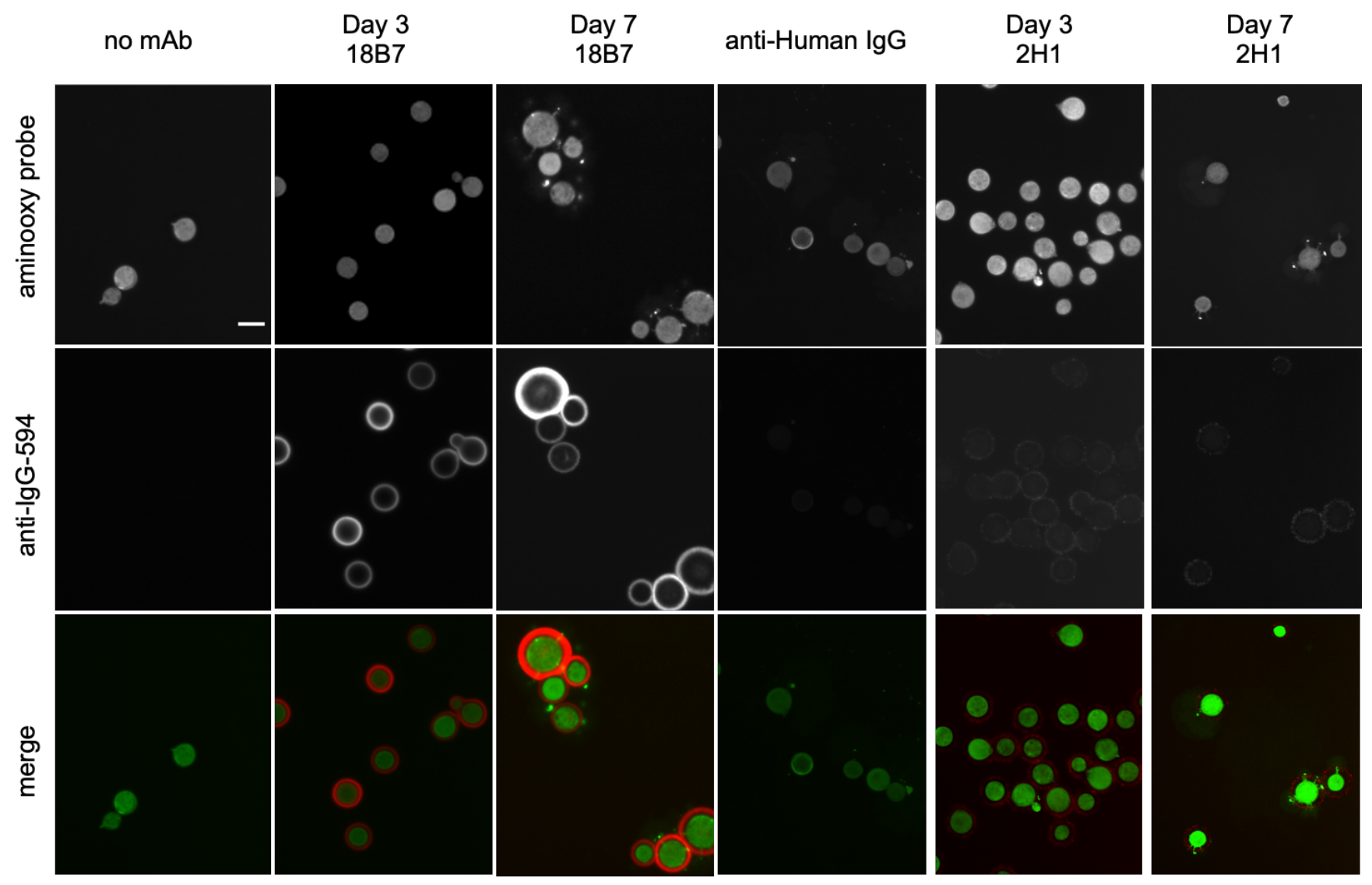

Figure 5. Fluorescent microscopy of heat-killed $\boldsymbol{C}$. neoformans cells incubated catalytic antibodies. Heat-killed cells were incubated with 18B7, 2H1, anti-human IgG or no antibody (no $\mathrm{mAb}$ ) and imaged on day 3 and 7 . An aminooxy probe was used to visualize the change in capsule architecture after exposure to catalytic antibodies over time. Scale bar $5 \mu \mathrm{m}$.

Despite this, there was an abundance of nucleophilic amino acids - tyrosine, histidine, and aspartate - which could work in tandem to produce acid-base catalysis to promote the observed glycosidase activity. Further we highlight the presence of two aspartate residues $8 \AA$ apart, about $20 \AA$ from the center of the binding cleft (SI, Figure 6). Highlighting the possibility that the catalytic residues may be 'near' the antigen-binding region rather than part of it. When performing the antibody-antigen docking experiments, it also became apparent that the P1 peptide and decasaccharide both compete for the same binding site, and are therefore "mimtopes" - mimics of epitopes, something previously suggested by Janda and Bowen et al. (SI, Figure 1). ${ }^{11,16,17}$ Further studies will be necessary to characterize the specific mechanism of action by $2 \mathrm{H} 1$.

\section{Capsule Measurements and Fluorescence Microscopy}

To discern if hydrolysis of the FRET probe by monoclonal antibodies predicted catalytic activity of the antibody on the capsule, we incubated cells with $10 \mu \mathrm{g} / \mathrm{mL}$ of $2 \mathrm{H} 1,18 \mathrm{~B} 7$, control IgG or no antibody for a week with heat killed H99 C. neoformans cells, at $30^{\circ} \mathrm{C}$ with agitation. After a week, the capsule was found to not significantly alter over time in the no antibody conditions, or with the incubation of the control $\mathrm{IgG}_{1}$ antibody. In contrast, cells incubated with mAbs $2 \mathrm{H} 1$ or $18 \mathrm{~B} 7$ showed a significant decrease in mean capsule diameter, suggesting antibody mediated catalysis/hydrolysis of the capsule $(p<0.0001)$. A population of cells incubated with either $18 \mathrm{~B} 7$ or $2 \mathrm{H} 1$, manifested the removal of the majority of their capsules, which parallels the finding that individual cells differ on their susceptibility to antibody hydrolysis (Figure 4B).
Further this indicates both that the antibodies have fine specificities, and that the capsules of $C$. neoformans are heterogenous even within the same strains, under the same growth conditions. ${ }^{6,8,11}$

We questioned if the catalytic antibodies were altering capsule architecture by changing the abundance of reducing end glycans in the capsule. Noting in our recent work in which we showed no reducing end glycans were present in the capsule, suggesting the capsule of $C$. neoformans bares similarities to those of prokaryotes. ${ }^{46,47}$ To investigate this, we heat-killed C. neoformans cells after they were grown in capsule inducing media for 3 days. Following this cells were incubated with the catalytic antibodies $18 \mathrm{~B} 7$ and $2 \mathrm{H} 1$, as well as a control $\mathrm{mAb}$ (mouse anti-human $\operatorname{IgG}_{1}$ ), and a no mAb control, after 3 and 7 days cells were visualized through fluorescence microscopy, using fluorescent anti-IgG secondary antibodies, and an hydroxylamine-armed fluorescent probe (RE probe), which labels reducing ends of polysaccharides. ${ }^{46}$ Under these conditions we see that both $18 \mathrm{~B} 7$ and $2 \mathrm{H} 1$ both recognize the capsule, but in differing patterns suggesting 2H1 and 18B7 may differ in epitope specificity (Figure 5). On day 3 , the majority of labelling by the hydroxylamine probe occurred intracellularly, and not in the capsule, suggesting initially when the capsule is hydrolyzed by $2 \mathrm{H} 1$ or $18 \mathrm{~B} 7$ that the polysaccharide does not remain associated with the capsule, and is released into the environment. This is supported by the decrease in mean capsule diameter of cells incubated with catalytic antibodies (Figure 4B, 4C). On day 7, the RE probe stained differently when compared to day 3 and controls, 
signaling a further change in capsule architecture (Figure 5). The RE probe was labelled in the capsule in both $18 \mathrm{~B} 7$ and $2 \mathrm{H} 1$ incubated cells, signaling the presence of reducing ends, possibly through hydrolyzed GXM fragments that remained associated to the capsule, possibly through divalent cations and hydrogen bonding. ${ }^{48}$ Considering the capsule measurements and fluorescence microscopy together it is clear that the capsule is undergoing changes when exposed to catalytic antibodies $2 \mathrm{H} 1$ and $18 \mathrm{~B} 7$. While the importance of this is yet to be fully resolved, it is known that the capsule is has immunosuppressive and anti-phagocytic properties, ${ }^{49,50}$ and antibody mediated hydrolysis of the capsule in vivo would likely have important immunological effects, decreasing the capsule diameter, possibly revealing more immunogenic structures, aiding the immune system to fight cryptococcal infection.

\section{Conclusion}

We present the design and synthesis of two oligosaccharide FRET probes, demonstrate their utility in characterizing the hydrolytic activity of four catalytic monoclonal antibodies, including anti-GXM 2H1, an antibody not previously known to be catalytic. To our knowledge, this is only the second report of an antibody with naturally occurring catalytic activity against glycans, and the most efficient identified to date. Using molecular docking studies, we predicted the interactions between $2 \mathrm{H} 1$ and its decasaccharide substrate. Since we were unable to identify the presence classical glycosidase active site, these observations could indicate further mechanisms yet to be discovered. The catalytic activity of $18 \mathrm{~B} 7$ and $2 \mathrm{H} 1 \mathrm{mAbs}$ observed against the synthetic FRET probe, was further exemplified on the native capsule of heat-killed $C$. neoformans cells, by decreasing the mean diameter of the capsule after incubation for 7 days. Differences in catalytic activity between $\mathrm{mAbs}_{3} \mathrm{E} 5 \mathrm{IgG}_{1}$ and $\mathrm{IgG}_{3}$ variants parallels similar observations made for peptide hydrolysis, ${ }^{17}$ which provides additional evidence of the fact that the constant region can affect catalytic activity for antibodies with identical variable regions. In future studies we will use these FRET probes as a diagnostic to identify new catalytic antibodies against the C. neoformans capsule from both serum and hybridoma technology. These FRET probes could also function as an assay to allow for the directed evolution of more efficient catalytic antibodies against the GXM, which could function both as important research tools and therapeutics.

\section{EXPERIMENTAL}

Microarray Printing Glycan array printing closely followed published procedures. ${ }^{51}$ Microarrays were constructed by piezoelectric non-contact printing (sciFLEXARRAYER S3, Scienion Inc) of the glycans on activated glass slides (Nexterion Slide H, Schott Inc). Compounds $(200 \mu \mathrm{M})$ were printed (drop volume $\sim 300 \mathrm{pL}, 6$ drop per spot), in replicates of 5 in sodium phosphate $(200 \mathrm{mM}), \mathrm{pH} 8.5$ buffer with on each slide. Overnight the slides were incubated in a humidity chamber, and the remaining activated esters were blocked with ethanolamine $(50 \mathrm{mM})$ in TRIS (100 mM), pH 8.0. Next, slides were rinsed with MilliQ water, dried by centrifugation, and stored at $4^{\circ} \mathrm{C}$. Hybridization of arrays was performed as described previously. ${ }^{51}$ Briefly, printed slides were blocked in a humidity chamber at $26^{\circ} \mathrm{C}$ for 2 hours with $2 \%$ BSA in PBS (pH 7.4 with $50 \mathrm{mM}$ ethanolamine), then washed 3 times for 2 minutes with PBS (pH 7.4, 0.1\% Tween-20) (PBS-T) and once for 3 minutes with PBS.
Microarray Screening Glycan array scanning followed published procedures. ${ }^{51}$ Primary anti-GXM mAbs or control Abs were prepared from stocks to the necessary concentration in 3\% BSA in PBS-T. Biotinylated goat anti-mouse kappa chain Abs were used as secondary reagents for all primary antibodies. Detection was performed with the streptavidin-conjugated SureLight P3 fluorophore (Cayman Chemical Company, Ann Arbor, MI) at $5 \mu \mathrm{g} / \mathrm{mL}$ in PBS-T. Scanning was performed first with the primary $A b$, then the secondary $A b$, then the fluorophore, with washes between each step. All hybridization steps were performed using the Agilent 8-well gasket system in a humidity-controlled rotating hybridization oven at $26^{\circ} \mathrm{C}$ for 1-2 hours. Washes (X3) in TRIS-buffered saline ( $\mathrm{pH} 7.6,0.1 \%$ Tween 20) (TBS-T) for 3 minutes and once for 3 minutes in TBS. Scanning was performed in an Agilent SureScan Dx microarray scanner with red wavelength emission detection. The data was processed on Mapix software. The mean fluorescent intensities (corrected for mean background) and standard deviations (SD) were calculated $(n=6)$. Data were fitted using Prism software (GraphPad Software, Inc). Bar graphs represent the mean $\pm \mathrm{SD}$ for each compound.

FRET Probe Synthesis Detailed protocols for the synthesis of novel compounds and their NMR characterization can be found in supporting information. Building blocks were synthesized as described previously. ${ }^{29,33,36,52}$

Growth Conditions C. neoformans Serotype A strain H99 (American Type Culture Collection (ATCC) 208821), was grown for $48 \mathrm{~h}$ at $30{ }^{\circ} \mathrm{C}$ in capsule inducing media composed of: $10 \mathrm{mM} \mathrm{MgSO}_{4}, 29.3 \mathrm{mM} \mathrm{KH} \mathrm{PO}_{4}, 13 \mathrm{mM}$ glycine, $3 \mu \mathrm{M}$ thiamine- $\mathrm{HCl}$; adjusted to $\mathrm{pH} 5.5$ and supplemented with 15 $\mathrm{mM}$ (regular minimal media) dextrose.

Kinetic experiments FRET experiments were completed as reported by Bowen et al. ${ }^{11}$ Using a SpectraMax M5 microplate reader (Molecular Devices), at $37^{\circ} \mathrm{C}$. An excitation wavelength of $320 \mathrm{~nm}$, an emission wavelength of $405 \mathrm{~nm}$, and an emission cut-off filter of $325 \mathrm{~nm}$.

Capsule digestion experiments $C$. neoformans cultures were grown to stationary phase under capsule-inducing conditions in minimal media ( 2 days). Starting culture conditions were complete in Sabouraud medium. Cells were collected and heat-killed at $60^{\circ} \mathrm{C}$ for $1 \mathrm{~h}$. Complete killing was confirmed by plating on solid Sabouraud medium. Heat-killed cells were washed 5 times with PBS to remove any soluble polysaccharide and cells were collected by ultracentrifugation $\left(4,000 \times \mathrm{g}, 5 \mathrm{~min}, 4{ }^{\circ} \mathrm{C}\right)$. Washed cells were suspended in a volume of PBS, which was divided equally between the four capsule digestion experiments: No mAb, control mAb (MOPC31C, Sigma), 18B7, 2H1. All antibody incubations were carried out at $10 \mu \mathrm{g} / \mathrm{mL}$. Each sample was diluted with PBS, $\mathrm{pH} 7.0$, to a final volume of $2 \mathrm{~mL}$ and a concentration of $10^{6}$ heat-killed cells $/ \mathrm{mL}$. Samples were then incubated at $37^{\circ} \mathrm{C}$ with agitation. C. neoformans capsules were visualized at day 0 and at day 7 under light microscopy, by mixing $2 \mu \mathrm{L}$ of India ink with $6 \mu \mathrm{L}$ of cells. Images were taken with an Olympus AX 70 microscope. Capsule measurements were completed (Fiji, NIH, USA) and compared to day 0 and day 7 (No mAb). Statistical analysis (Ordinary one-way ANOVA) was performed in GraphPad Prism (Version 8, GraphPad Software, La Jolla, CA).

Fluorescence microscopy As previously reported. ${ }^{46} \mathrm{H} 99$ C. neoformans cells were grown inoculated in Sabouraud dextrose medium for 2 days and then transferred to capsule inducing 
minimal media for 3 days. Samples were blocked in blocking buffer (1\% bovine serum albumin (BSA). Thereafter the cells were incubated with $2.5 \mu \mathrm{M}$ of the hydroxylamine fluorescent probe overnight at $30{ }^{\circ} \mathrm{C}$ in the dark. Cells were pelleted and washed to remove excess probe, X3 PBS plus 1\% BSA. Incubation with an $1 \mu \mathrm{g} / \mathrm{mL} \mathrm{IgG}_{1}$ 18B7-Alexa Fluor 594 conjugate for $1 \mathrm{~h}$, at $37^{\circ} \mathrm{C}$. Channel exposure: FITC (800 ms) (ex:em 498/516 nm), TRITC (600 ms) (ex:em 540/580 nm) and DAPI (50 ms) (ex:em 350/450 nm). Images were collected with an Olympus AX70 microscope, photographed with a QImaging Retiga 1300 digital camera using the QCapture Suite V2.46 software (QImaging, Burnaby BC, Canada), and processed with ImageJ or Fiji (NIH, USA).

\section{ASSOCIATED CONTENT}

\section{Supporting Information}

The Supporting Information is available free of charge on the ACS Publications website.

\section{AUTHOR INFORMATION}

\section{Corresponding Authors}

Arturo Casadevall - The Department of Molecular Microbiology and Immunology, Bloomberg School of Public Health, The Johns Hopkins University, Baltimore, Maryland 21205 orcid.org/0000-0002-9402-9167 E-mail: acasade1@jhu.edu

Stefan Oscarson - Centre for Synthesis and Chemical Biology, University College Dublin, Belfield, Dublin 4, Ireland orcid.org/0000-0002-8273-4918 E-mail: stefan.oscarson@ucd.ie

\section{Authors}

Conor Crawford - Centre for Synthesis and Chemical Biology, University College Dublin, Belfield, Dublin 4, Ireland and The Department of Molecular Microbiology and Immunology, Bloomberg School of Public Health, The Johns Hopkins University, Baltimore, Maryland 21205 orcid.org/0000-0002$\underline{1314-1019}$

Maggie P. Wear - The Department of Molecular Microbiology and Immunology, Bloomberg School of Public Health, The Johns Hopkins University, Baltimore, Maryland 21205

Daniel F. Q. Smith - The Department of Molecular Microbiology and Immunology, Bloomberg School of Public Health, The Johns Hopkins University, Baltimore, Maryland 21205

Clotilde d'Errico - Centre for Synthesis and Chemical Biology, University College Dublin, Belfield, Dublin 4, Ireland orcid.org/0000-0001-8996-4057

\section{Author Contributions}

C.C, A.C and S.O wrote the original draft. C.C completed the synthesis. C.C and C.D.E printed and screened the glycan array. C.C, M.P.W, D.F.Q.S completed the kinetic analysis. C.C completed the docking studies. C.C completed the capsule measurement experiments. D.F.Q.S, M.P.W completed the immunofluorescence experiments. All authors edited manuscript. C.C, A.C, S.O funding acquisition.

\section{ACKNOWLEDGMENTS}

We thank Dr Yannick Ortin and Dr Jimmy Muldoon for NMR and MS support. C.C was funded by Irish Research Council postgraduate award (GOIPG/2016/998). MPW was supported in part by AI007417. AC was supported in part by NIH grants AI052733 16 and HL059842 19. S.O was supported by Science Foundation Ireland Award 13/IA/1959.

\section{REFERENCES}

(1) Goldman, D. L.; Khine, H.; Abadi, J.; Lindenberg, D. J.; Pirofsk La; Niang, R.; Casadevall, A. Serologic Evidence for Cryptococcus Neoformans Infection in Early Childhood. Pediatrics 2001, 107 (5). https://doi.org/10.1542/peds.107.5.e66. Park, B. J.; Wannemuehler, K. A.; Marston, B. J.; Govender, N.; Pappas, P. G.; Chiller, T. M. Estimation of the Current Global Burden of Cryptococcal Meningitis among Persons Living with HIV/AIDS. AIDS 2009, 23 (4), 525-530. https://doi.org/10.1097/QAD.0b013e328322ffac.

Chow, S. K.; Casadevall, A. Evaluation of Cryptococcus Neoformans Galactoxylomannan-Protein Conjugate as Vaccine Candidate against Murine Cryptococcosis. Vaccine 2011, 29 (10), 1891-1898. https://doi.org/10.1016/j.vaccine.2010.12.134. Oscarson, S.; Alpe, M; Svahnberg, P.; Nakouzi, A; Casadevall, A. Synthesis and Immunological Studies of Glycoconjugates of Cryptococcus Neoformans Capsular Glucuronoxylomannan Oligosaccharide Structures. Vaccine 2005, 23 (30), 3961-3972. https://doi.org/10.1016/j.vaccine.2005.02.029.

Nakouzi, A.; Zhang, T.; Oscarson, S.; Casadevall, A. The Common Cryptococcus Neoformans Glucuronoxylomannan M2 Motif Elicits Non-Protective Antibodies. Vaccine 2009, 27 (27), 3513-3518. https://doi.org/10.1016/j.vaccine.2009.03.089.

Cherniak, R.; Valafar, H.; Morris, L. C.; Valafar, F. Cryptococcus Neoformans Chemotyping by Quantitative Analysis of $1 \mathrm{H}$ Nuclear Magnetic Resonance Spectra of Glucuronoxylomannans with a Computer-Simulated Artificial Neural Network. Clin. Diagn. Lab. Immunol. 1998, 5 (2), 146-159.

(7) Sheng, S.; Cherniak, R. Structure of the 13C-Enriched ODeacetylated Glucuronoxylomannan of Cryptococcus Neoformans Serotype A Determined by NMR Spectroscopy. Carbohydr. Res. 1997, $301 \quad$ (1-2), 33-40. https://doi.org/10.1016/S0008-6215(97)00084-0.

(8) Cherniak, R.; Sundstrom, J. B. Polysaccharide Antigens of the Capsule of Cryptococcus Neoformans. Infect. Immun. 1994, 62 (5), 1507-1512.

(9) Casadevall, A.; Dadachova, E.; Pirofski, L. A. Passive Antibody Therapy for Infectious Diseases. Nature Reviews Microbiology. September 2004, pp 695-703. https://doi.org/10.1038/nrmicro974.

(10) Larsen, R. A.; Pappas, P. G.; Perfect, J.; Aberg, J. A.; Casadevall A.; Cloud, G. A.; James, R.; Filler, S.; Dismukes, W. E. Phase I Evaluation of the Safety and Pharmacokinetics of MurineDerived Anticryptococcal Antibody 18B7 in Subjects with Treated Cryptococcal Meningitis. Antimicrob. Agents Chemother. 2005, $49 \quad$ (3), 952-958. https://doi.org/10.1128/AAC.49.3.952-958.2005.

(11) Bowen, A.; Wear, M. P.; Cordero, R. J. B.; Oscarson, S.; Casadevall, A. A Monoclonal Antibody to Cryptococcus Neoformans Glucuronoxylomannan Manifests Hydrolytic Activity for Both Peptides and Polysaccharides. J. Biol. Chem. 2017, $292 \quad$ (2), 417-434 https://doi.org/10.1074/jbc.M116.767582.

(12) William P. Jencks. Catalysis in Chemistry and Enzymology. $\begin{array}{llll}\text { Cour. Corp. } & \text { Sci. 1987, } & \end{array}$ https://doi.org/10.1126/science.168.3935.1080-a.

(13) Mets, B.; Winger, G.; Cabrera, C.; Seo, S.; Jamdar, S.; Yang, G.; Zhao, K.; Briscoe, R. J.; Almonte, R.; Woods, J. H.; et al. A Catalytic Antibody against Cocaine Prevents Cocaine's Reinforcing and Toxic Effects in Rats. Proc. Natl. Acad. Sci. U. S. A. 1998, 95 (17), 10176-10181. https://doi.org/10.1073/pnas.95.17.10176.

(14) Schultz, P. G. Catalytic Antibodies. Angew. chemie 1989, 28 (10), 
1283-1444.

Wentworth P., J.; Jones, L. H.; Wentworth, A. D.; Zhu, X.; Larsen, N. A.; Wilson, I. A.; Xu, X.; Goddard, W. A.; Janda, K. D.; Eschenmoser, A.; et al. Antibody Catalysis of the Oxidation of Water. Science (80-. ). 2001, 293 (5536), 1806-1811. https://doi.org/10.1126/science.1062722.

(16) Janda, A.; Eryilmaz, E.; Nakouzi, A.; Pohl, M. A.; Bowen, A.; Casadevall, A. Variable Region Identical IgA and IgE to Cryptococcus Neoformans Capsular Polysaccharide Manifest Specificity Differences. J. Biol. Chem. 2015, 290 (19), 1209012100. https://doi.org/10.1074/jbc.M114.618975.

(17) Janda, A.; Eryilmaz, E.; Nakouzi, A.; Cowburn, D.; Casadevall, A. Variable Region Identical Immunoglobulins Differing in Isotype Express Different Paratopes. J. Biol. Chem. 2012, 287 (42), 35409-35417. https://doi.org/10.1074/jbc.M112.404483.

(18) Hifumi, E.; Taguchi, H.; Toorisaka, E.; Uda, T. New Technologies to Introduce a Catalytic Function into Antibodies: A Unique Human Catalytic Antibody Light Chain Showing Degradation of $\beta$-Amyloid Molecule along with the Peptidase Activity. FASEB BioAdvances 2019, 1 (2), 93-104. https://doi.org/10.1096/fba.1025.

(19) Yang, G. Y.; Li, C.; Fischer, M.; Cairo, C. W.; Feng, Y.; Withers, S. G. A FRET Probe for Cell-Based Imaging of GangliosideProcessing Enzyme Activity and High-Throughput Screening. Angew. Chemie - Int. Ed. 2015, 54 (18), 5389-5393. https://doi.org/10.1002/anie.201411747.

(20) Cecioni, S.; Vocadlo, D. J. Carbohydrate Bis-Acetal-Based Substrates as Tunable Fluorescence-Quenched Probes for Monitoring Exo-Glycosidase Activity. J. Am. Chem. Soc 2017, 139, 53. https://doi.org/10.1021/jacs.7b01948.

(21) Sano, K.; Kuribara, T.; Ishii, N.; Kuroiwa, A.; Yoshihara, T.; Tobita, S.; Totani, K.; Matsuo, I. Fluorescence Quenching-Based Assay for Measuring Golgi Endo- $\alpha$-Mannosidase. Chem. - An Asian J. 2019, $14 \quad$ (11), 1965-1969. https://doi.org/10.1002/asia.201900240.

(22) Oka, H.; Koyama, T.; Hatano, K.; Matsuoka, K. Synthetic Studies of Bi-Fluorescence-Labeled Maltooligosaccharides as Substrates for $\alpha$-Amylase on the Basis of Fluorescence Resonance Energy Transfer (FRET). Bioorganic Med. Chem. 2012, 20 (1), 435-445. https://doi.org/10.1016/j.bmc.2011.10.065.

(23) Guerry, A.; Bernard, J.; Samain, E.; Fleury, E.; Cottaz, S.; Halila, S. Aniline-Catalyzed Reductive Amination as a Powerful Method for the Preparation of Reducing End-"Clickable" Chitooligosaccharides. Bioconjug. Chem. 2013, 24 (4), 544-549. https://doi.org/10.1021/bc3003716.

(24) Sistla, J. C.; Morla, S.; Alabbas, A. H. B.; Kalathur, R. C.; Sharon, C.; Patel, B. B.; Desai, U. R. Polymeric Fluorescent Heparin as One-Step FRET Substrate of Human Heparanase. Carbohydr. Polym. 2019, 205, 385-391. https://doi.org/10.1016/j.carbpol.2018.10.071.

(25) Guerry, A.; Bernard, J.; Samain, E.; Fleury, E.; Cottaz, S.; Halila, S. Aniline-Catalyzed Reductive Amination as a Powerful Method for the Preparation of Reducing End-"clickable" Chitooligosaccharides. Bioconjug. Chem. 2013, 24 (4), 544-549. https://doi.org/10.1021/bc3003716.

(26) Yuan, R. R.; Spira, G.; Oh, J.; Paizi, M.; Casadevall, A.; Scharff, M. D. Isotype Switching Increases Efficacy of Antibody Protection against Cryptococcus Neoformans Infection in Mice. Infect. Immun. 1998, 66 (3), 1057-1062.

(27) Varki, A.; Cummings, R. D.; Aebi, M.; Packer, N. H.; Seeberger, P. H.; Esko, J. D.; Stanley, P.; Hart, G.; Darvill, A.; Kinoshita, T.; et al. Symbol Nomenclature for Graphical Representations of Glycans. Glycobiology 2015, 25 (12), 1323-1324. https://doi.org/10.1093/glycob/cwv091.

(28) Guazzelli, L.; Ulc, R.; Oscarson, S. Synthesis of Benzyl Protected $\beta$-d-GlcA-( $1 \rightarrow 2)$ - $\alpha$-d-Man Thioglycoside Building Blocks for Construction of Cryptococcus Neoformans Capsular Polysaccharide Structures. Carbohydr. Res. 2014, 389 (1), 57-65. https://doi.org/10.1016/j.carres.2014.01.022.

(29) Guazzelli, L.; Ulc, R.; Rydner, L.; Oscarson, S. A Synthetic Strategy to Xylose-Containing Thioglycoside Tri- and Tetrasaccharide Building Blocks Corresponding to Cryptococcus Neoformans Capsular Polysaccharide Structures. Org. Biomol. Chem. 2015, 13 (23), 6598-6610. https://doi.org/10.1039/C5OB00766F.
Garegg, P. J.; Olsson, L.; Oscarson, S. Synthesis of Oligosaccharides Corresponding to Structures Found in Capsular Polysaccharides of Crytococcus Neoformans. Part 1. J. Carbohydr. Chem. 1993, 12 (7), 955-967. https://doi.org/10.1080/07328309308020108.

(31) Garegg, P. J.; Olsson, L.; Oscarson, S. Synthesis of Oligosaccharides Corresponding to Structures Found in Capsular Polysaccharides of Cryptococcus Neoformans . Part 3. Two Regioselectively Acetylated Tetrasaccharides. J. Carbohydr. Chem. 1997, $16 \quad$ (7), 973-981. https://doi.org/10.1080/07328309708005731.

(32) Alpe, M.; Oscarson, S.; Svahnberg, P. Synthesis of Cryptococcus Neoformans Capsular Polysaccharide Structures. IV. Construction of Thioglycoside Donor Blocks and Their Subsequent Assembly. J. Carbohydr. Chem. 2003, 22 (7), 565577. https://doi.org/10.1081/CAR-120026459.

(33) Guazzelli, L.; Ulc, R.; Bowen, A.; Crawford, C.; McCabe, O.; Jedlicka, A. J.; Wear, M. P.; Casadevall, A.; Oscarson, S. A Synthetic Glycan Array Containing Cryptococcus Neoformans Glucuronoxylomannan Capsular Polysaccharide Fragments Allows the Mapping of Protective Epitopes. ChemRxiv 2020. https://doi.org/10.26434/CHEMRXIV.11914905.V1.

(34) Fügedi, P.; Garegg, P. J. A Novel Promoter for the Efficient Construction of 1,2-Trans Linkages in Glycoside Synthesis, Using Thioglycosides as Glycosyl Donors. Carbohydr. Res. 1986, 149 (1), 9-12. https://doi.org/10.1016/S00086215(00)90385-9.

(35) Guazzelli, L.; Ulc, R.; Rydner, L.; Oscarson, S. A Synthetic Strategy to Xylose-Containing Thioglycoside Tri- and Tetrasaccharide Building Blocks Corresponding to Cryptococcus Neoformans Capsular Polysaccharide Structures. Org. Biomol. Chem. 2015, 13 (23), 6598-6610. https://doi.org/10.1039/c5ob00766f.

(36) Crawford, C.; Oscarson, S. Optimised Conditions for the Palladium-Catalyzed Hydrogenolysis of Benzyl and Naphthylmethyl Ethers: Preventing Saturation of Aromatic Protecting Groups. ChemRxiv 2020. https://doi.org/10.26434/CHEMRXIV.12030762.V2.

(37) Casadevall, A.; Mukherjee, J.; Devi, S. J. N.; Schneerson, R.; Robbins, J. B.; Scharff, M. D. Antibodies Elicited by a Cryptococcus Neoformans-Tetanus Toxoid Conjugate Vaccine Have the Same Specificity as Those Elicited in Infection. $J$. Infect. Dis. 1992, $165 \quad$ (6), 1086-1093. https://doi.org/10.1093/infdis/165.6.1086.

(38) Yuan, R.; Casadevall, A.; Spira, G.; Scharff, M. D. Isotype Switching from IgG3 to IgG1 Converts a Nonprotective Murine Antibody to Cryptococcus Neoformans into a Protective Antibody. J. Immunol. 1995, 154 (4), 1810-1816.

(39) Tull, D.; Withers, S. G. Mechanisms of Cellulases and Xylanases: $A$ Detailed Kinetic Study of the- $\beta-l$,4-Glycanase from Cellulomonas Fimúangle X-Ray Studies on Endoglucanase $A$ (CEN A) and Exoglycanase (Cex)* 1 from Cellulomonas Fimi Have Revealed a Tadpole-like Structure For; 1994; Vol. 33.

(40) Young, A. C. M.; Valadon, P.; Casadevall, A.; Scharff, M. D.; Sacchettini, J. C. The Three-Dimensional Structures of a Polysaccharide Binding Antibody to Cryptococcus Neoformans and Its Complex with a Peptide from a Phage Display Library: Implications for the Identification of Peptide Mimotopes. J. Mol. Biol. 1997, $274 \quad$ (4), 622-634. https://doi.org/10.1006/jmbi.1997.1407.

(41) Makeneni, S.; Thieker, D. F.; Woods, R. J. Applying Pose Clustering and MD Simulations to Eliminate False Positives in Molecular Docking. J. Chem. Inf. Model. 2018, 58 (3), 605-614. https://doi.org/10.1021/acs.jcim.7b00588.

(42) Nivedha, A. K.; Thieker, D. F.; Makeneni, S.; Hu, H.; Woods, R. J. Vina-Carb: Improving Glycosidic Angles during Carbohydrate Docking. J. Chem. Theory Comput. 2016, 12 (2), 892-901. https://doi.org/10.1021/acs.jctc.5b00834.

(43) Nivedha, A. K.; Makeneni, S.; Foley, B. L.; Tessier, M. B.; Woods, R. J. Importance of Ligand Conformational Energies in Carbohydrate Docking: Sorting the Wheat from the Chaff. $J$. Comput. Chem. 2014, 35 (7), 526-539. https://doi.org/10.1002/jcc.23517.

(44) Spiwok, V. $\mathrm{CH} / \pi$ Interactions in Carbohydrate Recognition. Molecules. MDPI AG July 1, 2017. 
(45)

https://doi.org/10.3390/molecules22071038.

Zechel, D. L.; Withers, S. G. Glycosidase Mechanisms: Anatomy of a Finely Tuned Catalyst. 2000. https://doi.org/10.1021/ar970172.

(46) Crawford, C. J.; Cordero, R. J. B.; Guazzelli, L.; Wear, M. P.; Bowen, A.; Oscarson, S.; Casadevall, A. Exploring Cryptococcus Neoforman s Capsule Structure and Assembly with a Hydroxylamine-Armed Fluorescent Probe. J. Biol. Chem. 2020, jbc.RA119.012251. https://doi.org/10.1074/jbc.ra119.012251. Whitfield, C. Biosynthesis and Assembly of Capsular Polysaccharides in Escherichia Coli. Annu. Rev. Biochem. 2006,

75 ,

$39-68$

https://doi.org/10.1146/annurev.biochem.75.103004.142545.

(48) Nimrichter, L.; Frases, S.; Cinelli, L. P.; Viana, N. B.; Nakouzi, A.; Travassos, L. R.; Casadevall, A.; Rodrigues, M. L. SelfAggregation of Cryptococcus Neoformans Capsular Glucuronoxylomannan Is Dependent on Divalent Cations \$. Eukaryot. Cell 2007, 6 (8), 1400-1410. https://doi.org/10.1128/EC.00122-07.
Cryptococcus Neoformans. Eukaryotic Cell. American Society for Microbiology (ASM) October 2004, pp 1067-1075. https://doi.org/10.1128/EC.3.5.1067-1075.2004.

Zaragoza, O.; Rodrigues, M. L.; De Jesus, M.; Frases, S.; Dadachova, E.; Casadevall, A. Chapter 4 The Capsule of the Fungal Pathogen Cryptococcus Neoformans. Advances in Applied Microbiology. 2009, pp 133-216. https://doi.org/10.1016/S0065-2164(09)01204-0.

(51) Kilcoyne, M.; Gerlach, J. Q.; Gough, R.; Gallagher, M. E.; Kane, M.; Carrington, S. D.; Joshi, L. Construction of a Natural Mucin Microarray and Interrogation for Biologically Relevant GlycoEpitopes. Anal. Chem 2012, 84, 2020. https://doi.org/10.1021/ac203404n.

(52) Guazzelli, L.; Ulc, R.; Oscarson, S. Synthesis of AGlucuronic Acid-Containing Thioglycoside Trisaccharide Building Block and Its Use in the Assembly of Cryptococcus Neoformans Capsular Polysaccharide $\quad$ Fragments**. https://doi.org/10.1002/open.201500143.

\section{Insert Table of Contents artwork here}



catalytic antibody epitope mapping
FRET probe synthesis
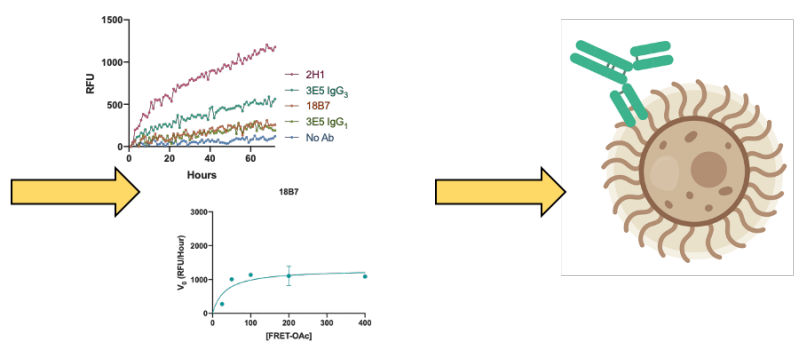

assay and determine kinetics native capsule! predict activity on 